\title{
Death Receptor in the First Year after Simultaneous Pancreas/Kidney Transplantation
}

\section{Marcelo G Sousa ${ }^{1-5 *}$, Marcelo M Linhares ${ }^{1-5}$, Alcides Salzedas ${ }^{3,5}$, Adriano M Gonzalez $^{3,5}$, Erika Rangel ${ }^{3,6}$, Joao R Sá ${ }^{3,7}$, Claudio Melaragno ${ }^{3,6}$, Leandro D Cezar ${ }^{2-5}$, Gaspar J L Lopes-Filho ${ }^{3,5}$ and Jose O M Pestana ${ }^{3,6}$}

${ }^{1}$ Participated in Research Design, São Paulo, Brazil

${ }^{2}$ Participated in the Writing of the Paper, São Paulo, Brazil

${ }^{3}$ Participated in the Performance of the Research, São Paulo, Brazil

${ }^{4}$ Participated in Data Analysis, São Paulo, Brazil

${ }^{5}$ Department of Surgery, Federal University of São Paulo, São Paulo, Brazil

${ }^{6}$ Department of Nephrology, Federal University of São Paulo, São Paulo, Brazil

${ }^{7}$ Department of Endocrinology, Federal University of São Paulo, São Paulo, Brazil

\begin{abstract}
Background: Simultaneous pancreas/kidney transplants require a long graft survival and recipient with to achieve more benefits than risks. In order to access the risk for this procedure, we evaluate the risk factors of death receptor with one year postoperatively in 292 simultaneous pancreas/kidney transplants evaluated 22 variables.

Materials and Methods: Twenty-two variables were selected for the study, nine from receivers, eight from donors and five variables related to the surgical procedure. To determine the survival of patients, we evaluated dates of transplants, the latest consultation and dates of deaths. All independent variables were compared with the dependent variable: patient lost in a year. Those with statistical significance through univariate analyzes, were also analyzed by multiple logistic regression technique in an attempt to develop a mathematical model capable of predicting 1-year patient loss.
\end{abstract}

Results: Relatively to the loss of patient in one year, the multivariate analysis identified body mass index receptor $(p \leq 0.008)$ and induction therapy (negative factor $p \leq 0.008$ ) as independent risk factors.

Conclusion: Based on the results of this research can be concluded that the independent variables related to one year loss of receptor are: body mass index of the donor and induction therapy.

Keywords: Pancreas transplantation; Kidney transplantation; Graft rejection; Risk factors; Type 1 Diabetes Mellitus; Multivariate analysis

\section{Introduction}

Diabetes Mellitus is a clinical syndrome with multiple etiologies; stems from lack of insulin or the inability to execute properly its function. It is characterized by chronic hyperglycemia with disturbances in the metabolism of carbohydrates, lipids and proteins. Without proper treatment, 20 years after the establishment of diabetes mellitus, $50 \%$ of these patients may have vision loss, kidney failure, motor disturbances, sensory disturbances and severe circulatory changes in microvascular changes caused by inadequate glycemic control [1-4].

The discovery of insulin in 1922 by a former theology student named Dr. Frederick Banting, not meant to cure, but only poor control of the disease, especially in its acute complications. Thus, despite several regimens available, the secondary problems are just postponed, because the ineffective control of metabolic abnormalities responsible for chronic changes, even with a restricted diet [5-7].

Pancreas transplantation is the only therapy to restore normoglycemia potential, enhance quality of life and prevent, stabilize or even reverse certain chronic complications of insulindependent diabetes mellitus patients; simultaneous pancreas/kidney transplantation, enables the return to a stage of normoglycemic insulin independence, and completes normalization of glycated hemoglobin levels. It's well accepted by the American Diabetes Association as the treatment of choice for type 1 diabetic patients with ends renal disease $[8,9]$.

It requires a long graft survival with transplanted pancreas in order to vest the lasting results of improved glycemic control in stabilization or regression secondary lesions of insulin dependent diabetes mellitus and to have more benefits than risks related to immunosuppression and complications of the surgical procedure $[3,10,11]$.

The best approach to anticipate and increasing the care before possible variables linked to the loss of the patient, would be to identify a set of variables related to donors, recipients and the surgical technique that, when inter-related, could identify or refer to the risks of medical transplant patient's death. Knowing that the survival benefit for the double transplant is greater after one year, it's important identify those patients with more potential to overcome this most critical period for the success of the procedure $[8,12,13]$.

Our idea is identify factors related to the patient's loss up to a year, even in the preoperative period, that associated with the potential donor recipients data, by the offer of an organ for transplantation, could help us to offer better chances of patient's survival.

\section{Materials and Methods}

We retrospectively studied 292 patients undergoing simultaneous

*Corresponding author: Marcelo Gonçalves Sousa, Department of Surgery, Federal University of São Paulo Rua Joakim Schuller 40 apto 705 , João Pessoa, Paraíba, Brazil, Tel: +558393324221; Fax: +558332228050; E-mail: mgscirurgia@ig.com.br

Received November 01, 2013; Accepted January 22, 2014; Published January 26, 2014

Citation: Sousa MG, Linhares MM, Salzedas A, Gonzalez AM, Rangel E, et al. (2014) Death Receptor in the First Year after Simultaneous Pancreas/Kidney Transplantation. J Nephrol Ther 4: 150. doi:10.4172/2161-0959.1000150

Copyright: ( 2014 Sousa MG, et al. This is an open-access article distributed under the terms of the Creative Commons Attribution License, which permits unrestricted use, distribution, and reproduction in any medium, provided the original author and source are credited. 
pancreas/kidney transplantation at the Federal University of São Paulo, in the period between December 2000 and November 2010.

The study included patients with insulin dependent diabetes mellitus with chronic complications as a result of a long period of hyperglycemia, which presented with chronic renal failure on conservative treatment with creatinine clearance less than $20 \mathrm{ml} /$ $\min / 1,73 \mathrm{~m}^{2}$ or already in replacement therapy and undergoing simultaneous pancreas/kidney transplantation.

The initial immunosuppression included Tacrolimus $0.15 \mathrm{mg} /$ $\mathrm{kg} /$ dose whose target dose was adjusted according to the time posttransplant (serum level of 10-15 ng/ml during the first 30 days, $8-10 \mathrm{ng} /$ $\mathrm{ml}$ between 31 and 90 days and $5-10 \mathrm{ng} / \mathrm{ml}$ thereafter); prednisone 0.5 $\mathrm{mg} / \mathrm{kg} /$ day (maximum $30 \mathrm{mg} /$ day and decrease of $5 \mathrm{mg}$ every month until a maintenance dose of $5 \mathrm{mg} /$ day from the sixth to eighth month of transplant); Mycophenolate Mofetil $2 \mathrm{~g} /$ day or mycophenolate sodium $1.44 \mathrm{~g} /$ day in all cases. The first 16 patients received cyclosporine to tacrolimus in place.

The intraoperative induction was performed with methylprednisolone (one gram intravenous) and Basiliximab $20 \mathrm{mg}$ intravenous. For patients with PRA (Panel Reactive Antibody test) $>30 \%$ or with delayed graft function in renal postoperatively, the option was the beginning of Thymoglobulin $(1 \mathrm{mg} / \mathrm{kg}$ /day with programming five days), and adjusted to dose in the peripheral lymphocyte count from the previous day. The recommendation for anuric patients was Thymoglobulin induction with tacrolimus and early in the fourth postoperative day, using a reduced dose of Mycophenolate sodium (360 $\mathrm{mg} /$ dose twice daily) until the fourth postoperative day. On the fourth postoperative day, was administered a second dose of Basiliximab 20 $\mathrm{mg}$ intravenously (except for patients who received Thymoglobulin).

There wasn't patient excluded from the evaluation because of any exclusion criterion, because all gone through a rigorous protocol, thus, in the case of a fairly homogeneous group.

The variables related to the donor were: age, Body Mass Index (BMI), creatinine, sodium and serum amylase, norepinephrine, cause of death (cardiocerebrovascular source/other) [5] and gender. The variables related to the surgical procedure were: cold ischemia time of pancreas, cold ischemia time of renal, following the implantation of organs, the type of duodenal anastomosis (enteral/bladder) and the type of venous drainage (cava/iliac). For the evaluation of the receiver, the following variables were used: age, body mass index, duration of dialysis, duration of diabetes, need for dialysis, gender, cyclosporine, use of induction therapy and type of preservation fluid (only belzer/ other combinations).

To determine the survival times of the patients were evaluated date of transplant, the latest consultation and date of deaths.

For all hypothesis tests performed, the significance level was set at 0.05. Initially, all the independent variables, as data donors, recipients, and surgical procedure are faced with the death receptor dependent variable with one year post-transplant [14]

Statistical analysis was performed using the SPSS 18.0 statistical package. The normality of continuous variables was checked by the Shapiro-Wilk. Univariate analysis was performed using the chi-square test and Student's $t$ test for independent measures or Mann-Whitney test [15].

Interpretation of the test medium or ranks (Mann-Whitney and $t$ test) was performed by comparing the mean or median between groups. In the table, T refers to the test result will Mann Whitney test $\mathrm{U}$ refers to the results of Mann-Whitney. The interpretation of the chisquare is by comparing the frequency of each category of the variable of interest between groups. When any given frequency table presented below five, reported to the value of the Fisher Exact [15-19].

We consider this study a significance level of $0.20(p \leq 0.20)$ for inclusion in the multivariate model. The odds ratios and corresponding confidence intervals of $95 \%$ were calculated, and evaluated significant in the final model at $\mathrm{p}<0.05$.

\section{Results}

We studied 292 patients who underwent simultaneous pancreas/ kidney transplants at the Federal University of São Paulo, from December 2000 to November 2010.

The mean age of patients was 36 years, ranging from 16 to 55 years. Regarding gender, 161 (55.1\%) were males and 131 (44.9\%) females.

There was no loss to follow-up in any case, the dates being considered for transplantation, graft loss, death and last contact.

Regarding donors, 179 (61.3\%) were male and 113 (38.7\%) females. There were $101(34.6 \%)$ disease deaths cardio cerebrovascular and other $191(65.4 \%)$ related to traumatic brain injury penetrating or blunt, anoxia or tumor, which were not considered together as cardio cerebrovascular. Norepinephrine in donors was necessary in 195 cases (66.8\%) for hemodynamic stabilization and 80 (27.4\%) were using dopamine in the last assessment before the capture of the organ.

Regarding the sequence of transplanted organs, the pancreas was initially implemented in $144(49.3 \%)$ patients and the kidney in 148 (50.7\%). In all access intraperitoneal transplantations was used for implantation into the extraperitoneal pancreas and kidney.

Regarding exocrine drainage during the first seven cases $(2.4 \%)$, fashioned to one and the other branch duodenovesical 285 (97.6\%) and a bypass duodenoileal lateral side [20].

In all cases, we used a graft "Y" iliac artery of the donor. Thus, in preparing the body (surgery table) were anastomosed the distal ends of the external and internal iliac arteries, respectively with the superior mesenteric artery and the splenic artery graft and surgery in the receiver, held an anastomosis Arterial with the right iliac artery of the recipient [20].

As the venous drainage, the donor's vein was anastomosed to the recipient vena cava in $106(36.3 \%)$ transplants and $186(63.7 \%)$ cases, this anastomosis was performed with the iliac vein of the recipient [20].

With regard to morbidity transplants were observed: 95 (32.5\%) patients with delayed renal function, the total loss of the pancreas during follow-up was $88(30.1 \%)$ cases, $57(19.5 \%)$ deaths, the main factor was the intra-abdominal sepsis, $49(16.8 \%)$ in these first year of transplantation simultaneous pancreas/kidney.

There were $56(18.2 \%)$ cases of pancreatic graft loss in three months post-transplant and between three months and one year $10(3.4 \%)$ totaling $66(22,6 \%)$ losses in the first year of transplantation. There were $30(10.3 \%)$ deaths with a functioning graft pancreatic until three months post-transplant and $9(3.1 \%)$ in the three months to a year. There were $21(7.2 \%)$ pancreatic losses one year after transplantation. Regarding the kidney, there were 75 (25.7\%) graft losses throughout the whole study.

The graft pancreatectomy was performed in 33 (11.3\%) patients, 25 
(8.6\%) in the first three months after surgery and the transplant was a case of pancreatic primary graft dysfunction.

The results of the univariate analyzes for the losses of patients with their respective frequencies and statistical analyzes are arranged in Tables 1 and 2.

Analyzing the variables in relation to the loss of the patient to a year, obtained a multivariate model based on body mass index receptor $(\mathrm{p} \leq 0.008$ ), induction (negative factor $\mathrm{p} \leq 0.008$ ) and a constant ( $\mathrm{p} \leq$ 0.000). The data are shown in Table 3.

\section{Discussion}

To have more benefits than risks associated with immunosuppression and complications of surgery are needed a long graft survival in pancreatic and increased survival of the recipient in order to vest the lasting results of improved glycemic control in stabilizing or even regression of secondary lesions of insulin dependent diabetes mellitus [3-11].

An evaluation later (up to one year post-transplant), aims to get the factors of losses not related necessarily to the technical fault. Thus, once the most delicate moment of the first three months after transplantation, we could predict those factors that were not related to the surgical procedure itself.

We know that to achieve better results with simultaneous pancreas/ kidney transplantation, we need to improve the survival of recipients, with survival for more than five years is that we have the real benefits of this modality $[8,12]$. According to the International Pancreas Transplant Registry-IPTR (2000-2004) survival in patients undergoing simultaneous pancreas/kidney transplantation was $95 \%$ in one year $[13,21,22]$

Through this analysis, we see the development of a mathematical model that enabled predict a greater or lesser chance of loss of patients since the preoperative period. Thus, we could optimize the characteristics of the donor, recipient and surgical techniques, to enable more selective and safer transplants, evaluating the most costeffective, but no disrespect to ethical issues.

By using initially the univariate analyzes of the data donors, surgical and recipients simultaneous pancreas/kidney transplants, in comparison with the variable loss of patients at one year (Tables 1 and 2 ), we noted that transplants performed with higher body mass indexes receptor and induction immunosuppressive therapy are associated with a higher likelihood of late loss patient.
In multivariate analysis (Table 3 ), only variables: body mass index and receptor induction immunosuppressive therapy and remained in the final statistical model of multiple logistic regression as the loss of patients at one year. These two variables have statistical significance individually within this mathematical model.

Understanding the factors for early losses and hence reduction of technical failure, late complications related to chronic immunosuppression also gained importance in attempting maintenance of pancreatic function lasting. Currently, nearly all the transplants simultaneous pancreas/kidney described in the literatures are induced with depleting or non-depleting drugs, hence the incidence of graft loss due to immune pancreatic the first year post-transplant decreased to $2.6 \%[13,22,23]$.

Our goal in using induction therapy, this type of transplant, was to reduce the incidence of acute rejection. We use induction therapy in $38.4 \%$ of patients, respecting our protocol and availability of drugs in our service. We use Antithymocyte globulin (antibodies depleting Thymoglobulin) or anti-IL2 (antibodies not depleting-Simulect ${ }^{\circledR}$ ) has not been made comparisons between modalities. Organ Procurement and Transplantation Network - OPTN data (2008) show that $52.9 \%$ of patients were induced with these drugs, while $33 \%$ received no induction [22].

The literature recommends the use of these agents to allow a more effective immunosuppression and enable withdrawal or phasing of the corticosteroid, as well as the reduction of the dosages of calcineurin inhibitors.

This protocol was submitted to the Ethics Committee of the Federal University of São Paulo, reviewed and approved under number $1383 \backslash 10$.

The use of therapy with depleting drugs is associated with lower incidence of rejection but cause a higher incidence of cytomegalovirus infections, without impacting on patient survival or graft. But our study clearly showed the protective effect of induction therapy to the patient with loss of one year at the same time pancreas transplant/kidney [24].

A prospective, randomized, multicenter study compared the use of antibody therapy depleting not without induction therapy and outcome in the first year showed fewer episodes of rejection, however the three years, there was no difference in survival in acute rejection episodes and morbidity [25]. The use of daclizumab induction (nondepleting agent) also was not associated with change in graft survival or patient elsewhere [26].

Becker et al. compared the induction therapy using basiliximab

\begin{tabular}{|c|c|c|c|c|c|c|c|c|c|c|c|c|c|c|}
\hline \multirow{3}{*}{ variables } & \multicolumn{12}{|c|}{ Loss patient with a year } & \multirow[t]{3}{*}{ t ou U } & \multirow[t]{3}{*}{$\mathbf{P}$} \\
\hline & \multicolumn{6}{|c|}{ No } & \multicolumn{6}{|c|}{ Yes } & & \\
\hline & $\mathbf{N}$ & Med. & SD & Median & Min. & Max. & $\mathbf{N}$ & Med. & SD & Median & Min. & Max. & & \\
\hline Donor Age & 244 & 26.3 & 9.3 & 23 & 10 & 46 & 48 & 27.9 & 9.7 & 25 & 10 & 45 & 5117.5 & $0, .67$ \\
\hline BMI donor & 244 & 23.6 & 2.8 & 23.79 & 11.57 & 32 & 48 & 23.9 & 3.0 & 24.11 & 12 & 29.2 & 5239 & 0.248 \\
\hline Donor creatinine & 244 & 1.2 & 0.6 & 1.075 & 0.3 & 3.93 & 48 & 1.2 & 0.4 & 1.1 & 0.4 & 1.97 & 5726.5 & 0.808 \\
\hline Sodium do doador & 244 & 154.8 & 16.5 & 154 & 114 & 200 & 48 & 157.1 & 14.7 & 157.5 & 126 & 189 & -0.885 & 0.377 \\
\hline Amylase donor & 244 & 163.4 & 231.0 & 89 & 10 & 1703 & 48 & 166.8 & 268.1 & 70 & 13 & 1345 & 5008 & 0.113 \\
\hline Pancreas Ischemia Time & 244 & 14.8 & 3.7 & 15 & 6 & 26.4 & 48 & 15.4 & 3.3 & 16 & 7 & 22 & -1.069 & 0.286 \\
\hline Renal Ischemia Time & 244 & 15.0 & 4.5 & 14,5 & 6 & 28 & 48 & 15.2 & 4.4 & 15 & 6 & 25 & 5637 & 0.682 \\
\hline Recipient age & 244 & 35.3 & 7.6 & 35 & 16 & 57 & 48 & 36.5 & 9.4 & 36 & 20 & 57 & 5398.5 & 0.392 \\
\hline BMI receiver & 244 & 21.6 & 3.0 & 21.095 & 15.78 & 36.5 & 48 & 22.8 & 3.7 & 22.255 & 16 & 34.3 & 4702 & 0.031 \\
\hline Diálise (months) & 244 & 32.6 & 19.6 & 31 & 0 & 108 & 48 & 33.6 & 25.5 & 31 & 0 & 120 & 5742 & 0.831 \\
\hline Diabetes (years) & 244 & 21.2 & 7.2 & 21 & 0 & 47 & 48 & 21.4 & 7.0 & 22 & 1 & 34 & 5535.5 & 0.548 \\
\hline
\end{tabular}

Table 1: Distribution of continuous variables simultaneously pancreas/kidney transplant according loss of the patient, one year, by univariate analysis. 
Citation: Sousa MG, Linhares MM, Salzedas A, Gonzalez AM, Rangel E, et al. (2014) Death Receptor in the First Year after Simultaneous Pancreas/ Kidney Transplantation. J Nephrol Ther 4: 150. doi:10.4172/2161-0959.1000150

Page 4 of 6

\begin{tabular}{|c|c|c|c|c|c|c|c|c|}
\hline \multirow{2}{*}{\multicolumn{2}{|c|}{ Variables }} & & \multicolumn{2}{|c|}{ Loss patient with a year } & \multirow{3}{*}{$\begin{array}{c}\text { Total } \\
179\end{array}$} & \multirow{2}{*}{$x^{2}$} & \multirow{2}{*}{$\mathbf{p}$} & \multirow{2}{*}{ Fisher $p$} \\
\hline & & & No & Yes & & & & \\
\hline \multirow{4}{*}{ Gender donor } & \multirow{2}{*}{ Male } & $\mathrm{N}$ & 150 & 29 & & \multirow{4}{*}{0.019} & \multirow{4}{*}{0.891} & \multirow{4}{*}{1.000} \\
\hline & & $\%$ & $83.8 \%$ & $16.2 \%$ & $100.0 \%$ & & & \\
\hline & \multirow{2}{*}{ Female } & $\mathrm{N}$ & 94 & 19 & 113 & & & \\
\hline & & $\%$ & $83.2 \%$ & $16.8 \%$ & $100.0 \%$ & & & \\
\hline & \multirow{2}{*}{ Total } & $\mathbf{N}$ & 244 & 48 & 292 & & & \\
\hline & & $\%$ & $83.6 \%$ & $16.4 \%$ & $100.0 \%$ & & & \\
\hline \multirow{4}{*}{ Causa Mortis } & \multirow{2}{*}{ Other } & $\mathrm{N}$ & 160 & 31 & 191 & & & \\
\hline & & $\%$ & $83.8 \%$ & $16.2 \%$ & $100.0 \%$ & 0017 & 0005 & 1000 \\
\hline & Corohro-vaccular & $\mathrm{N}$ & 84 & 17 & 101 & 0.017 & 0.895 & 1.000 \\
\hline & erebio-vascuial & $\%$ & $83.2 \%$ & $16.8 \%$ & $100.0 \%$ & & & \\
\hline & & $\mathbf{N}$ & 244 & 48 & 292 & & & \\
\hline & lotal & $\%$ & $83.6 \%$ & $16.4 \%$ & $100.0 \%$ & & & \\
\hline & $\mathrm{No}$ & $\mathrm{N}$ & 80 & 17 & 97 & & & \\
\hline Hre dr Nlomannoling & INO & $\%$ & $82.5 \%$ & $17.5 \%$ & $100.0 \%$ & 0105 & 0720 & 0730 \\
\hline Use que ivoracientamine & vec & $\mathrm{N}$ & 164 & 31 & 195 & 0.125 & 0.124 & 0.739 \\
\hline & yes & $\%$ & $84.1 \%$ & $15.9 \%$ & $100.0 \%$ & & & \\
\hline & Tatat & $\mathbf{N}$ & 244 & 48 & 292 & & & \\
\hline & Total & $\%$ & $83.6 \%$ & $16.4 \%$ & $100.0 \%$ & & & \\
\hline & Rim & $\mathrm{N}$ & 123 & 25 & 148 & & & \\
\hline Follawing Imnlant & Rim & $\%$ & $83.1 \%$ & $16.9 \%$ & $100.0 \%$ & 0005 & 0020 & 0075 \\
\hline Following Implant & Pâncrearc & $\mathrm{N}$ & 121 & 23 & 144 & 0.045 & 0.832 & $0.8 / 5$ \\
\hline & rancieds & $\%$ & $84.0 \%$ & $16.0 \%$ & $100.0 \%$ & & & \\
\hline & Tatal & $\mathbf{N}$ & 244 & 48 & 292 & & & \\
\hline & Iotal & $\%$ & $83.6 \%$ & $16.4 \%$ & $100.0 \%$ & & & \\
\hline & Bladder & $\mathrm{N}$ & 8 & 1 & 9 & & & \\
\hline then ongetomosic & Diaduer & $\%$ & $88.9 \%$ & $11.1 \%$ & $100.0 \%$ & 0100 & 0661 & 1000 \\
\hline type or andasiominsis & Enteral & $\mathrm{N}$ & 236 & 47 & 283 & 0.192 & 0.601 & 1.000 \\
\hline & Emitial & $\%$ & $83.4 \%$ & $16.6 \%$ & $100.0 \%$ & & & \\
\hline & TTht & $\mathbf{N}$ & 244 & 48 & 292 & & & \\
\hline & Iotal & $\%$ & $83.6 \%$ & $16.4 \%$ & $100.0 \%$ & & & \\
\hline & Cava & $\mathrm{N}$ & 89 & 17 & 106 & & & \\
\hline Trom Draina & Cavd & $\%$ & $84.0 \%$ & $16.0 \%$ & $100.0 \%$ & 0010 & - 000000 & 1000 \\
\hline Iype Drainage & lliar & $\mathrm{N}$ & 155 & 31 & 186 & 0.019 & 0.889 & 1.000 \\
\hline & mac & $\%$ & $83.3 \%$ & $16.7 \%$ & $100.0 \%$ & & & \\
\hline & Tatal 20 & $\mathbf{N}$ & 244 & 48 & 292 & & & \\
\hline & Iotal & $\%$ & $83.6 \%$ & $16.4 \%$ & $100.0 \%$ & & & \\
\hline & $\mathrm{No}$ & $\mathrm{N}$ & 187 & 34 & 221 & & & \\
\hline Continuous Ambulatory & NNO & $\%$ & $84.6 \%$ & $15.4 \%$ & $100.0 \%$ & 0725 & 0.201 & 0161 \\
\hline Peritoneal Dialysis & ves & $\mathrm{N}$ & 57 & 14 & 71 & 0.135 & 0.391 & 0.461 \\
\hline & yes & $\%$ & $80.3 \%$ & $19.7 \%$ & $100.0 \%$ & & & \\
\hline & Tatal & $\mathbf{N}$ & 244 & 48 & 292 & & & \\
\hline & Total & $\%$ & $83.6 \%$ & $16.4 \%$ & $100.0 \%$ & & & \\
\hline & Female & $\mathrm{N}$ & 111 & 20 & 131 & & & \\
\hline Sov resontar & remale & $\%$ & $84.7 \%$ & $15.3 \%$ & $100.0 \%$ & 0227 & 0626 & 0030 \\
\hline Sex receptor & Male & $\mathrm{N}$ & 133 & 28 & 161 & 0.231 & 0.626 & 0.038 \\
\hline & Male & $\%$ & $82.6 \%$ & $17.4 \%$ & $100.0 \%$ & & & \\
\hline & Tatal $>0$ & $\mathbf{N}$ & 244 & 48 & 292 & & & \\
\hline & lotal & $\%$ & $83.6 \%$ & $16.4 \%$ & $100.0 \%$ & . & & \\
\hline & $\mathrm{No}$ & $\mathrm{N}$ & 232 & 44 & 276 & & & \\
\hline 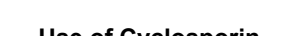 & INO & $\%$ & $84.1 \%$ & $15.9 \%$ & $100.0 \%$ & 0000 & 0212 & 0211 \\
\hline Use of Cyciosporin & Yol & $\mathrm{N}$ & 12 & 4 & 16 & 0.903 & 0.342 & 0.317 \\
\hline & Yes & $\%$ & $75.0 \%$ & $25.0 \%$ & $100.0 \%$ & & & \\
\hline & Tatat $>0$ & $\mathbf{N}$ & 244 & 48 & 292 & & & \\
\hline & Total & $\%$ & $83.6 \%$ & $16.4 \%$ & $100.0 \%$ & & & \\
\hline & $\mathrm{No}$ & $\mathrm{N}$ & 143 & 37 & 180 & & & \\
\hline Industion & TNO & $\%$ & $79.4 \%$ & $20.6 \%$ & $100.0 \%$ & 5701 & 0016 & (1002 \\
\hline Inauction & Yol & $\mathrm{N}$ & 101 & 11 & 112 & 3.191 & 0.016 & 0.022 \\
\hline & Tes & $\%$ & $90.2 \%$ & $9.8 \%$ & $100.0 \%$ & & & \\
\hline
\end{tabular}


Citation: Sousa MG, Linhares MM, Salzedas A, Gonzalez AM, Rangel E, et al. (2014) Death Receptor in the First Year after Simultaneous Pancreas/ Kidney Transplantation. J Nephrol Ther 4: 150. doi:10.4172/2161-0959.1000150

Page 5 of 6

\begin{tabular}{|c|c|c|c|c|c|c|c|c|}
\hline & Total & $\mathbf{N}$ & 244 & 48 & 292 & & & \\
\hline & tour & $\%$ & $83.6 \%$ & $16.4 \%$ & $100.0 \%$ & & & \\
\hline \multirow{6}{*}{ Perfusion } & \multirow{2}{*}{ No-Belzer } & $\mathrm{N}$ & 92 & 17 & 109 & \multirow{4}{*}{0.090} & \multirow{4}{*}{0.764} & \multirow{4}{*}{0.871} \\
\hline & & $\%$ & $84.4 \%$ & $15.6 \%$ & $100.0 \%$ & & & \\
\hline & \multirow{2}{*}{ Belzer } & $\mathrm{N}$ & 152 & 31 & 183 & & & \\
\hline & & $\%$ & $83.1 \%$ & $16.9 \%$ & $100.0 \%$ & & & \\
\hline & \multirow{2}{*}{ Total } & $\mathbf{N}$ & 244 & 48 & 292 & & & \\
\hline & & $\%$ & $83.6 \%$ & $16.4 \%$ & $100.0 \%$ & & & \\
\hline
\end{tabular}

Table 2: Distribution of categorical variables simultaneously pancreas/kidney transplant according loss of the patient, one year, by univariate analysis.

\begin{tabular}{|c|c|c|c|c|c|c|c|}
\hline \multirow{2}{*}{ Loss patient with a year } & \multirow{2}{*}{ B } & \multirow{2}{*}{ S.E. } & \multirow{2}{*}{$\mathbf{w}$} & \multirow{2}{*}{ Sig. } & \multirow{2}{*}{ (B) } & \multicolumn{2}{|c|}{ 95\% C.I. } \\
\hline & & & & & & Min. & Max. \\
\hline BMI receptor & .128 & .048 & 6.999 & .008 & 1.137 & 1.034 & 1.250 \\
\hline Induction (Yes) & -1.014 & .382 & 7.060 & .008 & .363 & .172 & .766 \\
\hline Constant & -4.150 & 1.085 & 14.624 & .000 & .016 & & \\
\hline
\end{tabular}

Table 3: Final result of the multiple logistic regression model for patients with loss of one year.

or daclizumab with immunosuppressive therapy without induction, combined modality pancreas/kidney. They observed no differences in patient survival or graft, but found higher mortality associated with sepsis in the group with induction, suggesting that transplantation without induction was safe and at lower cost [27].

Donors with body mass index greater than $30 \mathrm{~kg} / \mathrm{m}^{2}$ are associated with a greater number of surgical complications, especially infections and associated with thrombosis [28-30]. Other studies correlate with the loss pancreatic mass index greater than $30 \mathrm{~kg} / \mathrm{m}^{2}[1,13,21]$.

\section{Conclusions}

In assessing the risk factors of the patient's loss in the first year post simultaneous pancreas/kidney transplant, we conclude that the body mass index receptor and induction therapy are independent risk factors for these losses.

\section{Acknowledgments}

This research has no conflict of interest. This protocol was submitted to the Ethics Committee of the Universidade Federal de São Paulo, reviewed and approved under number $1383 \backslash 10$

\section{References}

1. Laemmli UK (1970) Cleavage of structural proteins during the assembly of the head of bacteriophage T4. Nature 227: 680-685.

2. Brusic V, Rudy G, Honeyman G, Hammer J, Harrison L (1998) Prediction of MHC class II-binding peptides using an evolutionary algorithm and artificial neural network. Bioinformatics 14: 121-130.

3. Doroshenko V, Airich L, Vitushkina M, Kolokolova A, Livshits V, et al. (2007) YddG from Escherichia coli promotes export of aromatic amino acids. FEMS Microbiol Lett 275: 312-318

4. Gores PF, Gillingham KJ, Dunn DL, Moudry-Munns KC, Najarian JS, et al. (1992) Donor hyperglycemia as a minor risk factor and immunologic variables as major risk factors for pancreas allograft loss in a multivariate analysis of a single institution's experience. Ann Surg 215: 217-230.

5. Krolewski AS, Warram JH, Christlieb AR, Busick EJ, Kahn CR (1985) The changing natural history of nephropathy in type I diabetes. Am J Med 78: 785794.

6. Sociedade Brasileira de Diabetes. Tratamento e acompanhamento do Diabetes Mellitus: diretrizes da Sociedade Brasileira de Diabetes [Internet]. São Paulo: Sociedade Brasileira de Diabetes; 2004 [citado 2008 Out 1]. Preparo pré e pós-operatório do paciente com diabetes mellitus; p. 142-45. Disponível em:

7. Zargar AH, Wani AA, Laway BA, Masoodi SR, Wani Al, et al. (2008) Prevalence of diabetes mellitus and other abnormalities of glucose tolerance in young adults aged 20-40 years in North India (Kashmir Valley). Diabetes Res Clin Pract 82: 276-281.

8. (1993) The effect of intensive treatment of diabetes on the development and progression of long-term complications in insulin-dependent diabetes mellitus. The Diabetes Control and Complications Trial Research Group. N Engl J Med 329: 977-986.

9. Margreiter R, Ofner D, Reinl E, Patsch J, Königsrainer A (1992) Pancreas transplantation--a critical appraisal. Transplant Proc 24: 2383-2386.

10. Ratner RE (1998) Type 2 diabetes mellitus: the grand overview. Diabet Med 15 Suppl 4: S4-7.

11. Gruessner RW, Sutherland DE, Gruessner AC (2004) Mortality assessment for pancreas transplants. Am J Transplant 4: 2018-2026.

12. Stratta RJ (1998). Impact of pancreas transplantation on the complications Curr Opin Organ Transplant 3(4): 258-73.

13. Davidson J, Dantal J, Dotta F, Haller H, Hernandez D, et al. (2003) New onset diabetes after transplantation: 2003 International consensus guidelines. Proceedings of an international expert panel meeting. Barcelona, Spain, 19 February 2003. Transplantation 27: 75(10 Suppl):SS3-24

14. Reddy KS, Stablein D, Taranto S, Stratta RJ, Johnston TD, et al. (2003) Longterm survival following simultaneous kidney-pancreas transplantation versus kidney transplantation alone in patients with type 1 diabetes mellitus and renal failure. Am J Kidney Dis 41: 464-470.

15. Troppmann C, Gruessner AC, Dunn DL, Sutherland DE, Gruessner RW (1998) Surgical complications requiring early relaparotomy after pancreas transplantation: a multivariate risk factor and economic impact analysis of the cyclosporine era. Ann Surg 227: 255-268.

16. Gruessner AC, Sutherland DE (2005) Pancreas transplant outcomes for United States (US) and non-US cases as reported to the United Network for Organ Sharing (UNOS) and the International Pancreas Transplant Registry (IPTR) as of June 2004. Clin Transplant 19: 433-55.

17. Kaplan EL, Meier P (1958) Nonparametric estimation from incomplete observations. J Am Stat Assoc 53(282): 457-81.

18. Statistical Package for the Social Sciences (2007), Version PASW Advanced Statistics 18.0 [Computer program]. Chicago (IL): SPSS Inc.

19. Cox DR (1972) Regression models and life-tables. J R Stat Soc Ser B. 34:187220.

20. Fletcher RH, Fletcher SW, Wagner EH (1996) Diagnóstico. In: Fletcher $\mathrm{RH}$, Fletcher SW, Wagner $\mathrm{EH}$, editores. Epidemiologia clínica: elementos essenciais. 3a ed. Porto Alegre: Artes Médicas; p. 52-83.

21. Cantor AB (2003) SAS survival analysis techniques for medical research. 2a ed. Cary (NC): SAS Publishing

22. Linhares MM, Azoulay D, Matos D, Castelo-Filho A, Triviño T, et al. (2006) Liver retransplantation: a model for determining long-term survival. Transplantation 81: 1016-1021.

23. Benedetti E, Sileri $P$ (2004) surgical aspects of pancreas transplantation. In: Gruessner RW, Sutherland DE, editores. Transplantation of the pancreas. New York: Springer-Verlag 74: 111-118.

24. Humar A, Khwaja K, Ramcharan T, Asolati M, Kandaswamy R, et al. (2003) 
Citation: Sousa MG, Linhares MM, Salzedas A, Gonzalez AM, Rangel E, et al. (2014) Death Receptor in the First Year after Simultaneous Pancreas/ Kidney Transplantation. J Nephrol Ther 4: 150. doi:10.4172/2161-0959.1000150

Chronic rejection: the next major challenge for pancreas transplant recipients. Transplantation 76: 918-923.

25. Gruessner AC (2011) 2011 update on pancreas transplantation: comprehensive trend analysis of 25,000 cases followed up over the course of twenty-four years at the International Pancreas Transplant Registry (IPTR). Rev Diabet Stud 8: 6-16.

26. Andreoni KA, Brayman KL, Guidinger MK, Sommers CM, Sung RS (2007) Kidney and pancreas transplantation in the United States, 1996-2005. Am J Transplant 7: 1359-1375.

27. Schmied BM, Müller SA, Mehrabi A, Welsch T, Büchler MW, et al (2006) Immunosuppressive standards in simultaneous kidney-pancreas transplantation. Clin Transplant 20 Suppl 17: 44-50.
28. Stratta RJ, Alloway RR, Lo A, Hodge EE (2005) A prospective, randomized multicenter study evaluating the safety and efficacy of two dosing regimens of daclizumab compared to no antibody induction in simultaneous kidneypancreas transplantation: results at 3 years. Transplant Proc 37: 3531-3534.

29. Becker LE, Nogueira VA, Abensur H, Miranda MP, Genzini T, et al. (2006) No induction versus anti-IL2R induction therapy in simultaneous kidney pancreas transplantation: a comparative analysis. Transplant Proc 38: 1933-1936.

30. Humar A, Ramcharan T, Kandaswamy R, Gruessner RW, Gruessner AG, et al. (2004) The impact of donor obesity on outcomes after cadaver pancreas transplants. Am J Transplant 4: 605-610. 